\title{
基于发展权价值评估的太湖东部水源保护区生态补偿标准”
}

\author{
陈江龙 ${ }^{1}$,姚 佳 ${ }^{1,2}$, 徐梦月 ${ }^{1,2}$, 陈 雯 ${ }^{1}$ \\ ( 1 : 中国科学院南京地理与湖泊研究所湖泊与环境国家重点实验室, 南京 210008) \\ (2: 中国科学院研究生院, 北京 100049$)$
}

\begin{abstract}
摘 要: 生态补偿是协调环境保护与区域发展机会公平的重要手段.太湖东部湖区是苏州市、嘉兴市和上海市重要饮用 水源供给地. 本文分析了苏州市滨湖地区水源地水质保护行为与发展权价值损失的关系. 应用区域比较法, 在地理要素 修正的基础上评价了太湖东部水源保护区发展权价值损失, 以此作为生态补偿的标准. 研究表明,2009 年太湖东部地区 水质保护行为的发展权损失为 42.39 亿元, 地方财政收人损失占 $75.88 \%$; 农民收人损失占 $13.58 \%$; 城镇居民收人损失 占 $10.53 \%$. 为了缩小城乡居民的收人差距,应优先对农民实施生态补偿. 水质保护行为产生的外部收益超出了水源供给 价值,需要在更大范围内统筹生态补偿问题.
\end{abstract}

关键词: 水源保护区; 发展权;生态补偿;太湖

\section{Eco-compensation of drinking water source protection region in eastern Lake Taihu based on development right valuation}

\section{CHEN Jianglong ${ }^{1}$, YAO Jia ${ }^{1,2}$, XU Mengyue ${ }^{1,2}$ \& CHEN Wen ${ }^{1}$}

(1: State Key Laboratory of Lake Science and Environment, Nanjing Institute of Geography and Limnology, Chinese Academy of Sciences, Nanjing 210008, P. R. China)

(2: Graduate University of Chinese Academy of Sciences, Beijing 100049, P. R. China)

\begin{abstract}
Ecological compensation is an important means to coordinate the contradiction between environmental protection and regional development fairness. Eastern Lake Taihu is an important source of drinking water for Suzhou, Jiaxing and Shanghai cities. This paper analyzes the connection between water quality protection behavior and loss of development right value in Suzhou city. Based on geographic factor correction, the paper applies regional comparison method to evaluate the loss of development right in drinking water source protection region in eastern Lake Taihu, as the standard of eco-compensation. It shows that the loss of development right in eastern Lake Taihu in 2009 is 4.239 billion yuan, while the loss of local fiscal revenue, farmers' income and urban residents' income accounting for $75.88 \%, 13.58 \%$ and $10.53 \%$, respectively. In order to narrow the income gap between urban and rural residents, farmers should be given priority on the implementation of eco-compensation. The external benefit from water protection behavior has beyond the value of water supply, so overall the eco-compensation police in a greater region is needed.
\end{abstract}

Keywords: Drinking water source protection region; development right; eco-compensation; Lake Taihu

生态补偿是当前政府和学术界关注的热点. 我国 1989 年正式提出了森林生态效益补偿的政策思路,此后, 生态补偿政策一直受到国家和各级政府的关注. 2007 年,原国家环境保护总局根据《国务院关于落实科学发展 观加强环境保护的决定》的精神,开展自然保护区、重要生态功能区、矿产资源开发和流域水环境保护等重点 领域生态补偿研究和试点工作. 国内外学者就生态补偿的理论基础、对象、原则、标准、方式进行了广泛的研 究 $^{[1-12]}$. 其中生态补偿标准的确定被学者们认为是实施生态补偿的难点. 目前, 确定生态补偿标准的研究方法 有多种,包括生态系统服务功能价值法、生态保护建设成本法、机会成本法、影子工程法、旅行费用法、支付意

* 中国科学院知识创新工程重要方向项目 (KZCX2-YW-339)、国家自然科学基金项目(41130750)和国家水体污染控 制与治理科技重大专项项目 (2008ZX07101-012) 联合资助. 2011-11-07 收稿;2011-11-23 收修改稿. 陈江龙, 男,1974 年生, 副研究员; E-mail: jlchen@ niglas. ac. cn. 
愿法、选择实验法等. 这些方法各具特点, 但在实际应用过程中由于条件以及方法的局限, 导致不同方法计算 的结论差异较大 ${ }^{[13]}$. 生态系统服务功能价值法在确定生态补偿标准方面理论依据最充分, 但目前关于生态系 统服务功能类型的理论划分比较复杂, 价值评估方法不成熟, 评价结果往往较难为社会所接受, 因而难以在生 态补偿的具体政策设计中应用 ${ }^{[14]}$. 支付意愿法、选择实验法测算的价格取决于个人的偏好, 实际操作上难以取 得可靠和正确的研究结果. 旅行费用法主要用在具有休憩价值的自然人文景观保护区的评估. 生态保护建设 成本法、机会成本法、影子工程法等方法在生态补偿标准测算中应用比较广泛 ${ }^{[8,13,15]}$.

流域水环境保护,特别是水源地环境保护是我国实施生态补偿的重点领域之一. 2007 年无锡市饮用水 危机引起了各级政府、企业和居民的广泛关注, 江苏省实施了 “铁腕治太” 的政策, 特别是实施产业结构调 整、加大力度治理工业污染和建设城乡污水集中处理设施以及加强监督与管理等有效地遏制了太湖水质恶 化的趋势. 然而这些方针政策与管制规则的实施, 也给为保护饮用水源安全而限制发展的沿湖地方政府和 人民带来了负面效应, 即以产业发展为主要内容的区域发展权受到了限制, 政府财政收人、城乡居民收人严 重缩水. 如何保障水源保护区区域公共服务的有效供给、城乡居民生活水平稳步提升成为保障太湖水环境 持续稳定改善所必须解决的关键问题. 建立有效的生态补偿机制是解决该问题的重要途径之一, 而合理地 确定生态补偿标准则是关键中的关键. 太湖东部湖体是苏州、嘉兴和上海市主要的饮用水源供给地, 研究该 区域生态补偿问题,对于长三角一体化协调发展具有重要的实践指导意义.

\section{1 研究区域概况}

本文以《江苏省太湖水污染防治条例》规定的太湖湖体、沿湖岸五公里一级保护区为基本依据. 选择太 湖东部地区苏州市沿湖乡镇为重点研究区域对象, 兼顾乡级行政边界的完整性, 该研究区东北部边界以京 杭运河相城段西岸边坡为准(图 1), 研究区域土地利用现状见图 2. 涉及相城区的望亭镇, 高新区的通安镇、 东渚镇、镇湖街道, 吴中区的金庭镇、临湖镇、东山镇、光福镇、胥口镇、香山街道、越溪街道、横泾街道, 吴江 市的松陵镇、横扇镇、七都镇. 研究区陆域总面积 $82044.08 \mathrm{hm}^{2}, 2009$ 年总人口 99.15 万人, 城镇化水平 $40 \%$, 人均财政收人 1.1 万元, 但各个街道 (镇) 之间差异较大, 财政收人最高乡镇是最低乡镇的 13.75 倍. 该区湖体自北向南分布有金墅港、渔洋山、浦庄、镇湖、庙港等饮用水源地, 以及太浦河清水通道饮用水源 地, 日均为苏州市、上海市、嘉兴市提供 $900 \times 10^{4} \mathrm{~m}^{3}$ 用水. 太湖饮用水源地均以取水口为中心划定一、二级及 准保护区,陆域部分属于涵养水源的保护区, 本文将研究区域统称为水源保护区. 该区域是苏州市、上海市、 嘉兴市重要水源地, 生态功能十分重要, 同时又是发展条件较好的区域, 研究该区域的生态补偿对于经济发 达的平原河网地区跨界生态保护具有重要的借鉴意义.

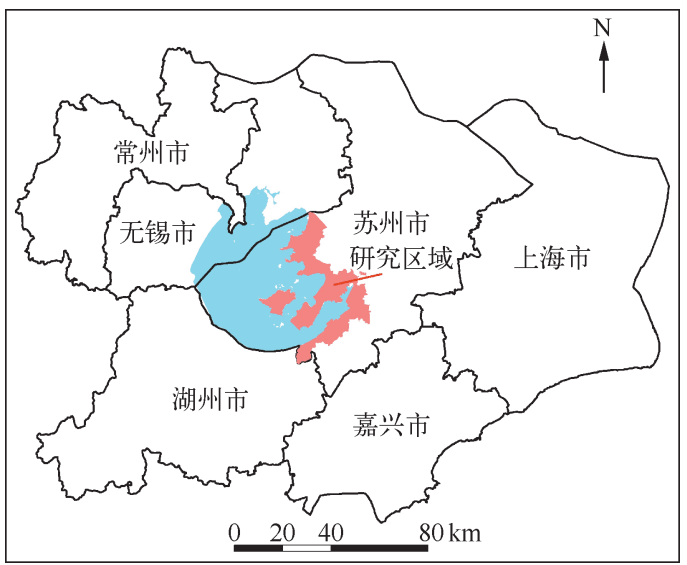

图 1 研究区域区位示意图

Fig. 1 Location of study area

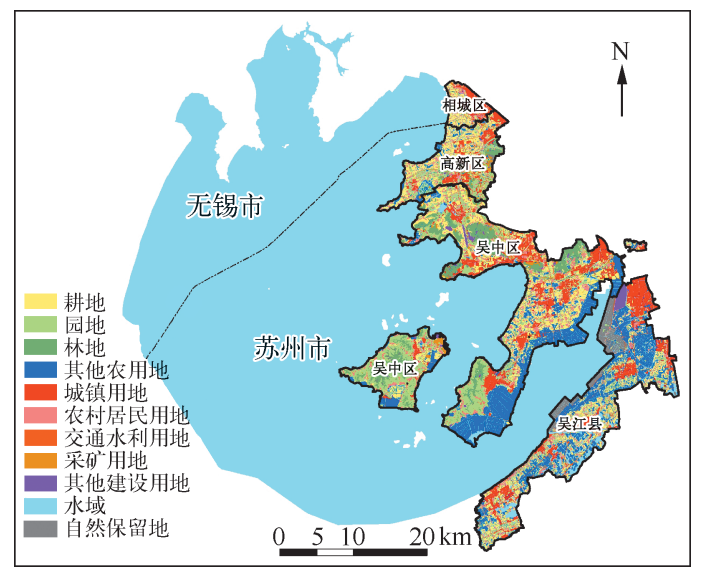

图 2 研究区域土地利用现状

Fig. 2 Current land-use in study area 


\section{2 水源保护与发展权价值损失}

\section{1 发展权的内涵}

联合国大会 1986 年通过的《发展权利宣言》把发展权规定为“发展权利是一项不可剥夺的人权,个人和 所有各国人民都有权参与、促进并享受经济、社会、文化和政治发展,在这种发展中,所有人权和基本自由都 能获得充分实现”. 发展权是关于发展机会均等和发展利益共享的权利 ${ }^{[16]}$. 土地发展权是发展权在经济上 重要的实现方式. 土地发展权是指土地变更用途使用和对土地原有集约度的改变之权,土地发展权包括农 地发展权和市地发展权 ${ }^{[17]}$. 农地发展权是指土地用途由农用地转为非农用地的权利及在农地使用性质不变 的情况下扩大投人的权利. 市地发展权是指建设用地原有利用集约度 (如容积率) 的改变之权. 土地用途和 土地利用强度是土地发展权的物质要素, 这些物质要素的价值形态就是土地发展权价值构成. 具体包括: （1）土地用途变更所产生的价值变化; (2) 土地利用强度变更所产生的价值变化; (3) 体现在土地用途与利 用强度价值中区位变化所产生的价值变化 ${ }^{[18]}$.

\section{2 水源保护对发展权价值的影响}

根据国家、江苏省和苏州市在太湖水环境治理中的要求,研究区域内产业发展受到了一定的限制. 主要 包括: (1) 产业进人的限制,污染型的产业禁止新建和扩建. 一级保护区内全面禁止原料工业发展,严格限 制一般加工工业. 这些措施提高地方政府招商引资的难度,减少了财政收人来源. 由于非农产业发展滞后, 当地居民非农就业的机会减少, 收人也随之减少. (2) 对纺织染整、化工、食品 (啤酒、味精) 等重点行业的排 污企业, 实施工业废水提标改造和深度处理工程. 由于污染排放标准提高, 大多数企业转移到了外地, 进一 步减少了地方政府税收收人和居民的就业机会. (3) 太湖湖体围网养殖面积大幅度缩减, 如东太湖 2007 年 围网面积 $113.2 \mathrm{~km}^{2}, 2008$ 年缩减为 $30 \mathrm{~km}^{2}$, 减少了 $73.5 \%$, 湖区渔民的收人大大减少. (4) 环太湖 $1 \mathrm{~km}$ 及 主要人湖河道上溯 $10 \mathrm{~km}$ 两侧 $1 \mathrm{~km}$ 范围为畜禽禁养区. 环太湖 $1 \sim 5 \mathrm{~km}$ 为限养区, 禁止新建畜禽养殖场, 实 行粪污无害化处理和农牧结合, 达到零排放; 对不符合环保要求的畜禽养殖场, 限期治理或强制关闭. 这些 措施也减少了当地农民的收人来源.

研究区域由于实施水环境保护,发展机会明显少于其他地方. 表现在土地发展权上就是土地非农开发 受限制, 且增值收益减少. 政府由于财政收人减少, 投资公共服务设施建设能力明显减弱. 当地居民由于产 业发展受到限制, 非农就业机会减少, 收人也相比其他区域少. 农民进行高收益农业经营行为也受到限制, 减少了土地利用强度提升的收益, 造成收人上的损失. 由于用途变更和强度变更受到限制, 经济发展的集聚 效应减弱, 区位优势提升的增值收益也减少. 根据 2009 年的数据统计,处于水源保护区的东山镇和金庭镇 年人均可支配收人为 13100 元和 9900 元, 仅为吴中区平均水平的 $38.5 \%$ 和 $29.1 \%$, 苏州市平均水平的 $43.8 \%$ 和 $33.1 \%$. 近 $5 \mathrm{a}$ 来, 人均可支配收人的平均增速东山镇为 $10.8 \%$, 金庭镇为 $13.1 \%$, 远低于苏州市 的 $14.8 \%$ 、吴中区的 $17.0 \%$ 和相城区的 $21.0 \%$. 东山与金庭两镇由 20 世纪七八十年代苏州地区村镇中最 富裕的地区, 滑落为纯收人最低的地区.

总体上,研究区域在水环境保护中为了公共利益做出了特别的牺牲. 发展权受到了损失,按照公平正义 的原则,应当由全体人民 (受益区) 对这部分人民作出的特别牺牲进行补偿 ${ }^{[19]}$.

\section{3 太湖东部水源保护区发展权损失补偿估算}

由以上的分析可知,发展权的损失表现在发展利益上主要包括居民享受公共服务供给和自身购买力的 损失. 因此, 对发展权的补偿既要补偿居民收人的损失, 也要补偿公共服务供给能力的损失. 现有的研 究 $^{[20-21]}$ 主要针对居民收人损失补偿是不全面的.

\section{1 发展权价值损失评价方法}

对于发展权损失评估实质是对水环境保护行为投人产出效益的评价. 水环境保护行为在限制自身发展 的同时也会带来收益, 如优美的生态环境带来的旅游收人、有机农产品的收人等. 保护区财政收人、城乡居 民收人就是实施保护行为下的收益. 保护行为的成本可以用机会成本法来估算,一项决策的机会成本是作 出某一决策而不作出另一种最优决策时所放弃的东西 ${ }^{[22]}$, 在水环境保护中就是保护者所放弃的最大利益, 也就是发展权的客观价值. 按照生态补偿的原则, 如果环境保护行为的收益大于成本, 则不需要进行补偿; 如果收益小于成本,则需对差距部分进行补偿,以体现公平的原则. 
机会成本的评价可以借用土地评估中的市场比较法, 即选择与研究区域发展条件相似的地区为参考 系,通过影响地方财政收人、人均收人的要素修正,估算研究区域发展权的损失,具体公式为:

$$
P=\left(G_{0}-G\right) N+\left(F_{0}-F\right) n_{1}+\left(R_{0}-R\right) n_{2}
$$

式中, $P$ 为补偿金额; $G_{0}$ 为参照地区人均地方财政收人; $G$ 为水源保护区人均地方财政收人; $N$ 为水源保护区 的总人口数量; $F_{0}$ 为参照地区农民人均纯收人; $F$ 为水源保护区农民人均纯收人; $n_{1}$ 为水源保护区的农业总 人口数量 $; R_{0}$ 为参照地区城镇居民人均可支配收人 $; R$ 为水源保护区的城镇居民人均可支配收人; $n_{2}$ 为水源 保护区的城镇居民总人口数量.

\section{2 发展权价值的地理要素修正}

上述方法的关键在于将待评估区域的人均财政收人、城镇居民收人和农民收人修正为在参照区域发展 条件的收人. 现有的研究一般将参照地区的数据与待评估区域直接对比 ${ }^{[20]}$. 然而财政收人、城乡居民收人具 有天然的空间异质性特征, 如果没有进行数据的修正, 将影响评价结果的科学性. 影响区域发展的地学因素 包括自然条件、区位因素、资源基础、生态环境和基础设施等 ${ }^{[23]}$. 自然条件包括地形地貌、地质条件、自然灾 害等要素. 区位因素反映事物的空间关系, 在全球化背景下, 与主要出海口和经济核心区的相对位置关系成 为决定地区区位优势的主要因素. 资源基础包括矿产资源、土地资源、水资源等要素. 生态环境条件主要是 指各区域的生态环境承载力. 基础设施主要包括交通设施、通信设施、能源供应及供水设施等. 财政收人、城 乡居民收人是区域发展的函数. 故财政收人、城乡居民收人与所处区域的自然条件、资源禀赋、区位条件等 自然、人文要素息息相关. 通过地理要素的修正可以进一步提高补偿标准确定的准确度.

为提高参照地区与评估地区的可比性, 本文以乡镇为基本评价单元, 选择同一行政区内自然条件相似 的临近乡镇作为参照乡镇,分别为相城区的黄埭镇、高新区的娄葑镇、吴中区的胜浦镇、吴江市的锦溪镇.

研究区域内地形、气候、水土资源供给等自然和资源要素的差异较小, 生态环境要素和基础设施条件也 相似. 在进行参照系数修正时主要考虑交通区位条件对人均财政收人、城乡收人的影响. 以水源保护区乡镇 为单元, 将乡镇的人均财政收人、农民人均纯收人和城镇居民人均可支配收人分别作为被解释变量, 以到苏 州市和上海市的交通可达性作为解释变量, 进行回归分析, 根据回归结果, 确定解释变量对被解释变量的作 用方向和贡献率, 从而形成发展评估的修正体系; 得到修正数据后, 与选定的参照区域进行对比, 得到水源 保护区因保护水源地生态环境而导致政府财政和居民收人受损的价值.

选择包括水源保护区乡镇和和参照乡镇的人均财政收人 $\left(y_{1}\right)$ 、农民人均纯收人 $\left(y_{2}\right)$ 和城镇居民人均可 支配收人 $\left(y_{3}\right)$ 以及到苏州市最短距离 $\left(x_{1}\right)$ 和上海市最短距离 $\left(x_{2}\right)$ 分别作为回归分析的被解释变量和解释 变量, 利用 SPSS 统计软件进行回归分析. 结果表明, $x_{1}$ 均未能通过显著性检验, $x_{2}$ 均通过了显著性检验. 上海 市对研究区域乡镇财政和居民收人的辐射影响远高于苏州市. 故以到上海的可达性因素对水源保护区内的 乡镇人均财政收人、农民人均纯收人和城镇居民人均可支配收人进行区位因素修正, 最终得修正后的水源 保护区社会经济数据 (表 1 ).

\section{3 生态补偿标准确定}

2009 年相城区因保护水环境而损失的发展权价值 $P_{1}$ 为 23672.4 万元. 同理, 高新区、吴中区和吴江市因 保护水环境而损失的发展权价值 $P_{2} 、 P_{3}$ 和 $P_{4}$ 分别为 $233688.8 、 144676.8 、 21830.6$ 万元. 2009 年, 太湖东部饮 用水源保护区发展权损失价值为 423868.5 万元 (表 2 ).

\section{4 结论与讨论}

\section{1 发展权补偿的范围}

水源保护区由于实施了严格的产业准人门槛和污染治理标准, 经济增长受到阻碍, 地方政府财政收人 受到损失, 弱化了提供公共服务的能力. 城乡居民就业机会相对变少, 高收益的土地利用行为受到约束, 收 人也随之降低, 也就是发展机会均等和发展利益共享的权利受到了损失, 这是为了提供水源这种公共产品而做 出的特别牺牲. 按照公平正义的原则必须对水源保护区损失的发展权价值做出补偿. 现有的研究对于发展权损失 补偿仅测算城乡居民收人损失部分 ${ }^{[20,24]}$. 按照联合国《发展权利宣言》, 国家有权利和义务制定适当的国家发展政 策, 其目的是在全体人民和所有个人积极、自由和有意义地参与发展及其带来的利益公平分配的基础上, 不断改善 全体人民和所有个人的福利. 个人的福利既受收人的影响, 也受公共服务供给能力的影响. 因此, 补偿由于实施环 境保护行为而损失的发展权价值应当包括政府的财政收人和城乡居民收人两部分损失. 
表 12009 年水源保护区与参照区域修正后社会经济数据 *

Tab. 1 Revised socio-economic data of drinking water source protection and reference regions in 2009

\begin{tabular}{|c|c|c|c|c|c|c|c|}
\hline 区域 & 乡镇 & $\begin{array}{c}\text { 人均财政 } \\
\text { 收人/(元/年) }\end{array}$ & $\begin{array}{c}\text { 农民人均 } \\
\text { 纯收人/(元/年) }\end{array}$ & $\begin{array}{l}\text { 城镇居民可支配 } \\
\text { 收人/(元/年) }\end{array}$ & $\begin{array}{l}\text { 总人口 } \\
\text { /人 }\end{array}$ & $\begin{array}{c}\text { 农业人口 } \\
\text { /人 }\end{array}$ & $\begin{array}{c}\text { 城镇人口 } \\
/ \text { 人 }\end{array}$ \\
\hline 相城区 & 望亭镇 & 6001.7 & 14367.6 & 24381.1 & 70384.0 & 38711.2 & 31672.8 \\
\hline 参照区域 & 黄埭镇 & 8286.8 & 15100.0 & 25882.0 & - & - & - \\
\hline \multirow[t]{3}{*}{ 高新区 } & 通安镇 & 5601.4 & 10241.0 & 20670.0 & 56988.0 & 38751.8 & 18236.2 \\
\hline & 东渚镇 & 2780.4 & 13808.8 & 18113.4 & 43118.0 & 29320.2 & 13797.8 \\
\hline & 镇湖街道 & 13700.2 & 16171.1 & 25255.6 & 24436.0 & 16616.5 & 7819.5 \\
\hline 参照区域 & 娄葑镇 & 18540.3 & 17558.0 & 30350.0 & - & - & - \\
\hline \multirow[t]{8}{*}{ 吴中区 } & 金庭镇 & 6108.6 & 17833.2 & 46534.2 & 49443.0 & 29665.8 & 19777.2 \\
\hline & 临湖镇 & 8660.0 & 19568.6 & 34283.5 & 62930.0 & 37758.0 & 25172.0 \\
\hline & 东山镇 & 8551.5 & 17528.9 & 45220.8 & 56056.0 & 33633.6 & 22422.4 \\
\hline & 光福镇 & 8244.1 & 21234.1 & 36791.1 & 64220.0 & 38532.0 & 25688.0 \\
\hline & 胥口镇 & 13753.8 & 21242.7 & 46655.7 & 88891.0 & 53334.6 & 35556.4 \\
\hline & 香山街道 & 7422.6 & 21260.8 & 50350.7 & 112470.0 & 67482.0 & 44988.0 \\
\hline & 越溪街道 & 12721.2 & 20991.9 & 41322.3 & 25833.0 & 15499.8 & 10333.2 \\
\hline & 横泾街道 & 13231.4 & 20691.8 & 37311.8 & 31905.0 & 19143.0 & 12762.0 \\
\hline 参照区域 & 胜浦镇 & 11803.7 & 19830.0 & 34830.0 & - & - & - \\
\hline \multirow[t]{3}{*}{ 吴江市 } & 松陵镇 & 39842.1 & 21507.2 & 39021.5 & 192390.0 & 111586.2 & 80803.8 \\
\hline & 横扇镇 & 10958.9 & 17583.5 & 33965.7 & 43484.0 & 25220.7 & 18263.3 \\
\hline & 七都镇 & 12261.3 & 17798.4 & 34129.0 & 68927.0 & 39977.7 & 28949.3 \\
\hline 参照区域 & 锦溪镇 & 12979.9 & 18956.0 & 30188.0 & - & - & - \\
\hline
\end{tabular}

* 资料来源:《苏州市统计年鉴 $(2010)$ 》、《2010 年苏州市国民经济和社会发展统计公报》.

表 2 水源保护区发展权损失

Tab. 2 Loss of development right of drinking water source protection region

\begin{tabular}{ccccc}
\hline 区域 & 地方财政收人损失/万元 & 农民纯收人损失/万元 & 城镇居民可支配损失/万元 & 合计/万元 \\
\hline 相城区 & 16083.5 & 2835.1 & 4753.7 & 23672.4 \\
高新区 & 153516.9 & 41651.8 & 38520.0 & 233688.8 \\
吴中区 & 138306.6 & 4994.6 & 1375.6 & 144676.8 \\
吴江市 & 13741.4 & 8089.1 & 0 & 21830.6 \\
合计 & 321648.5 & 57570.7 & 44649.3 & 423868.5 \\
\hline
\end{tabular}

\section{2 发展权损失补偿的条件与方法完善}

评价发展权损失的关键是确定环境保护行为的机会成本, 可以借鉴土地评估中的市场比较法,即选择 与受损区域发展的自然人文条件相似且发展现状代表保护区所在区域正常水平的行政单元作为参照系. 将弥补两个区域之间人均财政收人、城乡居民收人的差距作为实现发展权利均等的生态补偿标准. 从生态 产品供给方的角度看, 生态补偿的数量应该是实施环境保护行为的净损失量, 也就是环境保护收益扣除环 境保护成本的净值. 当净值大于零时, 环境保护的收益大于成本, 则不需要进行生态补偿. 区域比较法是度 量机会成本确定环境保护行为损益的有效方法, 相比纯理论的生态服务价值法、支付意愿法 ${ }^{[9,12]}$, 本方法具 有较好的操作性. 地方财政收人、城乡居民收人受区域自然和人文等地理要素的影响, 具有空间异质性, 进 行区域比较时必须进行地理要素的修正,这是本文在生态补偿标准确定上的创新.

\section{3 水源保护区生态补偿标准与导向}

根据发展权损失的评估结果, 2009 年太湖东部水源保护区为保护水环境而损失的发展权价值是 42.39 亿. 其中, 财政收入损失 32.16 亿, 占总损失的 $75.88 \%$; 农民收人损失 5.76 亿, 占总损失的 $13.58 \%$; 城镇居 民的收人损失 4.46 亿, 占总损失的 $10.53 \%$. 从各个行政区发展权损失的比例上看, 吴江市农民收人损失占 
本区域总损失的 $37.05 \%$, 这与吴江市大规模减少网围养殖面积有很大的关系. 高新区和吴中区农民收人损 失的绝对值较大. 为了缩小城乡居民的收人差距, 应优先对农民实施生态补偿. 对农民的补偿应根据受水源 保护制度约束的大小确定补偿的优先序, 根据水源一级、二级、准保护区及水源涵养区确定补偿区域的优先 序,但根据渔民、一般农民确定补偿类型的优先序.

从生态服务价值的角度看, 太湖东部地区环境保护行为产生的生态服务功能包括气候调节、涵养水源、 水土保持、净化环境、防洪蓄洪、维持生物多样性、景观服务等. 与水源供给直接相关的功能主要是涵养水 源、水土保持、净化环境, 其余的生态服务功能是水源保护行为产生的外部性效益. 因此, 如何细致地甄别出 水源保护行为产生的各种生态功能的价值及其受益者, 从而将太湖东部地区水环境保护行为的外部性完全 内化并合理分摊保护成本需要进一步深人研究. 目前以水源供给为主要目标的保护行为的受益者涵盖江浙 沪三地,需要根据各地的取水量合理分摊太湖东部地区的发展权损失. 具体的补偿标准可以依据本文的研 究结果, 根据受偿者的需求和补偿者的支付能力及支付意愿, 通过政府间的协商确定. 目前国家正在大力推 进长三角地区一体化的进程, 核心是通过合理的区域功能分工, 达到生态环境成本最低、经济效益最高的发 展状态. 功能分工必将产生区域发展权的转移, 从而需要合理的生态补偿, 本文的研究方法可以为长三角实 施区域管治提供政府间协商的方法论支撑.

\section{5 参考文献}

[ 1 ] 蒋天中, 李 波. 关于建立农业环境污染和生态破坏补偿法规的探讨. 农业环境保护, 1990, 9(2) : 29-30, 33.

[2] 章 铮. 生态环境补偿费的若干基本问题. 北京: 中国环境科学出版社, 1995.

[ 3 ] 庄国泰, 高 鹏, 王学军. 中国生态环境补偿费的理论与实践. 中国环境科学, 1995, 15 (6) : 413-418.

[4] 叶文虎, 魏 斌, 圭 川等. 城市生态补偿能力衡量和应用. 中国环境科学, 1998, 4: 298-301.

[ 5 ] 黄富祥, 康慕宜. 退耕还林还草过程中的经济补偿问题探讨. 生态学报, 2002, 22(4)：471-478.

[ 6 ] Pagiola S, Ramírez E, Gobbi J et al. Paying for the environmental services of silvopastoral practices in Nicaragua. Ecological Economics, 2007, 64(2): 374-385.

[ 7 ] Engel S, Pagiola S, Wunder S. Designing payments for environmental services in theory and practice: An overview of the issues. Ecological Economics, 2008, 65: 663-674.

[8] 程 颐. 饮用水源保护区生态补偿机制构建初探一一厦门案例研究. 环境科学与管理, 2008, 33(7): 141-147.

[ 9 ] 赵 旭, 杨志峰, 徐琳瑜. 饮用水源保护区生态服务补偿研究与应用. 生态学报, 2008, 28(7): 152-159.

[10] 戴其文, 赵雪雁. 生态补偿机制中若干关键科学问题——甘南藏族自治州草地生态系统为例. 地理学报, 2010, 65(4) : 494-506.

[11］赵翠薇, 王世杰. 生态补偿效益、标准一一国际经验及对我国的启示. 地理研究, 2010, 29(4) : 597-608.

[12] 李 青, 张落成, 武清华. 太湖上游水源保护区生态补偿支付意愿问卷调查一以天目湖流域为例. 湖泊科学, $2011,23(1)$ : 143-149.

[13] 李晓光, 苗 鸿, 郑 华等. 机会成本法在确定生态补偿标准中的应用一以海南中部山区为例. 生态学报, $2009,29(9): 10-18$.

[14] 任 勇, 冯东方, 俞 海. 中国生态补偿理论与政策框架设计. 北京: 中国环境科学出版社, 2008.

[15］周大杰, 桑燕鸿, 李惠民等. 流域水资源生态补偿标准初探一以官厅水库流域为例. 河北农业大学学报, 2009, 32(1): 10-13.

［16］刘安华. 农民政治发展权保障的困境与出路. 中共云南省委党校学报, 2011，12(2)：159-162.

[17］藏俊梅，王万茂，陈茵茵. 农地发展权价值的经济学分析. 经济体制改革, 2008,(4) : 90-95.

［18］邹钟星, 祝平衡. 土地发展权价格的测算方法. 统计与决策, 2009, (4) : 156-158.

[19］陈新民. 德国公法学基础理论. 济南：山东人民出版社, 2001.

[20］郑海霞，张陆彪. 流域生态服务补偿定量标准研究. 环境保护, 2006, (1A)：42-46.

[21] 李晓光, 苗 鸿, 郑 华等. 机会成本法在确定生态补偿标准中的应用一以海南中部山区为例. 生态学报, 2009, 29(9) : 4875-4883.

[22］ [美]保罗. A. 萨缪尔森. 经济学. 北京: 中国发展出版社, 1992.

[23] 陆大道, 刘卫东. 论我国区域发展与区域政策的地学基础. 地理科学, 2000, 20(6): 487-493.

[24] 李平星, 孙 威. 经济地理学角度的区域生态补偿机制研究. 生态环境学报, 2010, 19(6) : 1507-1512. 